\title{
FRAMEWORK INCORPORATING SYNCHRONIZED PHASOR DATA FOR POWER SYSTEM OPERATION AND CONTROL
}

\author{
Yiming Wu, Kun Zhu, Moustafa Chenine and Lars Nordström \\ Dept. of Industrial Information and Control Systems \\ KTH - Royal Institute of Technology, Sweden \\ Email: yimingw@ics.kth.se
}

\begin{abstract}
This position paper presents initial research and investigation on a unified framework combining two independent systems, the legacy SCADA system and the synchronized phasor data system, that share the same measurement sources, i.e., current and voltage transducers and the same communication medium. In this framework, conventional SCADA system coupled with substation automation system are modeled together with synchronized phasor systems. The contribution of this paper also includes a state-ofthe-art survey of topics related to the proposed architectures. Furthermore, an overview of the data flows between substation and control centers including both SCADA and phasor measurements are presented. Taking into consideration the growing interest in communication and automation standardization this paper also addresses the communication between the substations coupled with relevant standards and technology.
\end{abstract}

Key works: Framework, Synchronized phasor data, Quality of Service (QoS), Overlay control

\section{INTRODUCTION}

Control centers run as a crucial part of power system. With development of computational ability, application algorithms, communication technology, infrastructure, and power system equipment control centers keep upgrading from analog to digital computation and communication [1-3]. Supervisory Control and Data Acquisition (SCADA) system is also following this development. Primarily control center focuses on balance of generation and consumption, and market operation. Comprehensive data acquisition and improved security of operation it has been possible to withstand disturbances and contingencies. Moreover, competitive power markets are driving a move from vertically centralized utilities to a decentralized system.

Synchronized phasor technology has been envisioned as an enabler for advanced wide-area monitoring, control and protection system [4].
Research efforts have been focused on developing new PMU based applications and supporting Information and Communication Technologies (ICT) [5]. Current power grid operation depends on SCADA system which was initially proposed in 70s [2]. The limited communication bandwidth coupled with limited computation power resulted that SCADA systems in general support very low data transfer rate, i.e., 1 sample per 2 seconds. As a result of rapid advancement in communication technology, current synchronized phasor measurement can reach resolutions up to 60 samples per second [4,6]. There has been several research initiatives aiming to incorporate phasor data with the legacy systems. On the other hand, the majority of them do hold the belief that the phasor measurement systems should be considered as independent system running in parallel with the legacy SCADA system due to their different requirements in terms of resolutions and synchronization [7-9].

SCADA and wide area monitoring (WAM) system are decoupled in recent power system operations. A research of unified framework to incorporate these two systems for power system operation and control is presented in this paper.

The rest of the paper is organized as following: Section 2 presents a survey of the legacy SCADA system and relevant power system applications. Section 3 presents synchronized measurement technology and phasor data based applications. Section 4 shortly describes the standards and guidelines relevant to framework. Section 5 states some requirement of the system. Finally proposed framework and future work is given.

\section{LEGACY SCADA SYSTEM POWER SYSTEM APPLICATION}

AND

\subsection{SCADA system architecture}

SCADA system is composed of field measurement devices such as current and voltage transducers (CTs/VTs), signal processor, communication components (e.g., RTUs), and control center applications. Figure 1 gives a general overview of the SCADA system. Substation measurement 
devices are implemented to obtain real time data. These measurements are transferred to control center by communication network.

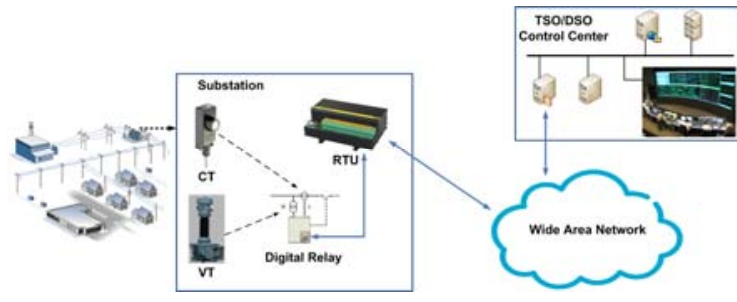

Fig. 1 : SCADA System Overview

SCADA system evolution can be divided into four stages. In the 70s, SCADA system was proposed after introducing digital computing in control and operation electric power industry. Due to the limitation of computational ability, communication technique, and infrastructure, control and operation system was divided into two levels. Control center level holds overview control of wide area power system generation and transmission. Substation level focuses on substation field control. Mechanical relays are the primary devices in substation. Copper wired based analog communication is mainly used between mechanical relays, transducers, switches, breakers, and RTUs. Limited communication bandwidth restricted number of data source and data rate from field substations to control centers. Integrated circuit (IC) chips brought SCADA system into next stage of evolution. Digital protection relays were introduced to the power industry as cost was decreased significantly with development in IC technology. Digital computation capability simplifies protection scheme realization. However, digital relays were still copper wired with RTU to communicate with control center. In third stage, functions in relays and RTUs were overlapped. Logical control computation was available in RTUs. By implementing field bus technique, relays obtained digital communication capability. As new concept of Intelligent Electronic Device (IED) came into vision, now any device contains one or more processors with capability of receiving or sending data/control from or to an external source can be called IED [10]. RTUs, digital relays, IEDs are vendor specified devices. Consequently interoperability and reliability requirements have become of significant importance which will be discussed in later section. Synchronized

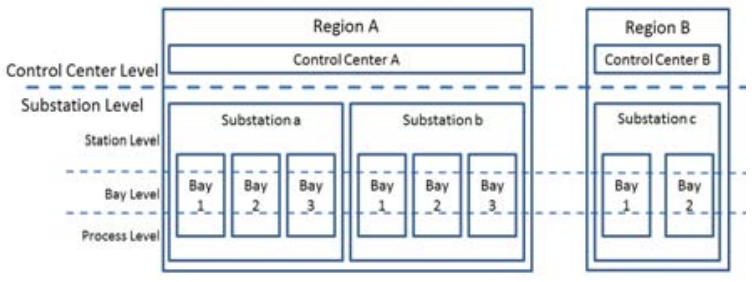

Fig. 2 : SCADA System Architecture measurement technology was proposed in past decades [11]. Phasor Measurement Units (PMUs) integrate both measurement and communication ability which allow them to provide real-time data to control applications directly. Except individual measurement transducer, PMUs can also share transducer with IEDs [12].

Figure 2 shows the SCADA system architecture where the system is divided into several levels [13]. In one region, control centers are located in control center level. Control centers take responsibility of monitoring and control substations in this region. Each substation has three hierarchical levels, station level, bay level, and process level, according to different proposed functions. Implementation of IT makes it possible to transfer data cross different levels and regions. Work done in [2] presents SCADA architecture integrated with business management system (BMS) where BMS transfers the planning of the system operation and schedules of contracts to EMS, meanwhile, EMS provides system constraints to BMS for further decision. Serviceoriented concept moves centralized EMS application to small size distributed control center $[7,8,14]$. Control and protection functionality can be located at any place where wide area measurements are able to merge into the system $[15,16]$.

From what has been discussed above, information technology (IT) is a primary requirement for modern power system. Integrating power and communication infrastructures is a growing trend $[17,18]$. Legacy SCADA system is vendor dependent isolated and closed network. The automation systems and applications of it are not designed for open public network [19]. Requirement of cybersecurity comes with the evolution of SCADA system which will be discussed in the later section.

\subsection{Power system applications and corresponding data requirements}

Power system applications can be divided into two main groups according to information flows. One is control center applications and the other is substation applications. Control center automation system holds overview of the wide area power network. Power generation, transmission operation, protection and control of wide system are its main jobs. Combined with electricity market, modern energy management system is implemented in control center [2]. On the other hand, applications in the substation are focusing on power system secure operation, equipment protection and maintenance [20,21]. Most substation automation systems only have the scope of local substation. For some specified functions, they need to communicate with other substations. 


\subsubsection{Control Center applications}

For the control center application, input of control function such as voltage, current, frequency comes from substation metering equipment. Control command issued to generation unit and substation can be seen as output.

In control center, SCADA system takes responsibility of data acquisition and command issue. SCADA system has several common functions [22]:

- Data Acquisition (DA)

- Human Machine Interface (HMI)

- Supervisory Control

- Alarm Processing

- Information storage and Reports

- Sequence of Events Acquisition

- Data Calculations

- $\quad$ Special RTU Processing/Control

Applications for power system operation and control combined into EMS. Some common applications are list as blow [2]:

- $\quad$ State Estimation (SE)

- $\quad$ Contingency Analysis (CA)

- Security-Constrained Unit Commitment (SCUC)

- Security-Constrained Economic Dispatch (SCED)

- Automatic Generation Control (AGC)

- $\quad$ Power System Stabilizing (PSS)

- Load Management (LM)

They use obtained information from SCADA system as input. Their output can be used for supervisory control command or assistant for operator to make the decision.

\subsubsection{Substation applications}

Most substation applications are based on the input collected locally. In some applications, they are also using input data from other substation directly or from control center. The common substation applications preliminarily are divided into several main categories based on protecting objects: line protection, transformer protection, generator protection, bus-bar protection, and fault location [23-25]. Line protection is further divided into two sub-categories based on the voltage level at which the line is operated. One is protection for transmission lines such as:

- Distance protection

- Differential protection

- $\quad$ Phase comparison protection

- Transient measuring protection

The other is protection for distribution feeders:

- Over current protection

- Differential protection

For other primary equipment such as: Transformer, Generator, and Busbar, differential protection is the most common protection type.
Fault location is another important application that orients from protection. The difference is that protection needs to respond in case of fault, whereas fault location analysis will give answers for the exact location of the fault. Fault location is implemented to locate the occurred fault as accuracy as possible. It has different algorithm approaches based on different network topology [25].

\section{SYNCHRONIZED MEASUREMENT TECHNIQUE AND APPLICATIONS}

Synchronized measurement technology (SMT) is a crucial technology enabling wide area monitoring, protection and control system [12]. Phasor Measurement Unit (PMU) is the device measures the electrical waves in different location of the power system grid. PMUs are synchronized to a common time source, i.e., Global Position System (GPS), to calculate the phasors. Measurement part is connected with transducer to collect real-time value of voltage and current. Filter is implemented in this part to remove the DC offset or higher-order harmonics. Analog signal is quantized and processed by digital signal processing algorithms (DSP) to identified magnitude, frequency, and phase angles. Communication part connects with network to send out data stream [26].

The phasor data concentrator (PDC) is another important element in the WAM, WAP, and WAC systems. Its core function is to collect phasor data from its connected PMUs and sort them according their time stamps. Once a data packet containing all phasors with the same time stamp is collected completely, the PDC forwards the encapsulated packet to the upper-stream applications where the data is consumed [27]. If necessary, PDC may down sample the synchronized phasors according to requirement of upper-stream applications [49]. The PDC could also have other functionalities, such as error checking and archiving for off-line or historical data analysis, see [28] and [29] for the details.

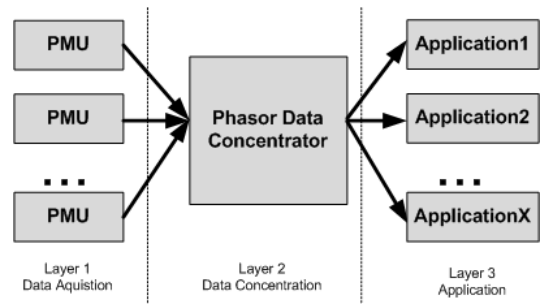

Fig. 3 : Phasor data flow in WAM, WAP, and WAC systems

Figure 3 shows the phasor data stream, created by PMU located in data acquisition lay, flows through PDC, who concentrates several phasor data stream from different PMUs, to end user applications of WAM, WAP, and WAC systems. 
The wide-area monitoring applications in general fall into the following three categories: assistance in operator decision-making, i.e., phasor measurement based state estimations [57]; off-line analysis after major system events, i.e., postmortem analysis; and finally, model verification and instrument calibrations [30,31]. For monitoring purposes, the ICT system is designed to collect voluminous data at dispersed locations over entire network. It is common for the WAM system to operate based on remote measurements taken from PMUs out of its responsible territory for applications such as seams between state estimation [31]. The system for control purposes is either of a distributed or a centralized architecture. The PMU-based distributed control is commonly performed on a limited input dataset and performs control action within a closed loop. Probably, the most well-addressed distributed control case is to apply synchronized phasors to damp the inter-area oscillations [32]. Alternatively, there are also proposals for centralized control applications based on phasor information, i.e., fast load-shedding for voltage control [33].

\section{RELEVANT STANDARDS GUIDELINES}

AND

As discussed above, most power system equipment and systems are vendor dependent. Communication between devices from different vendors could be resource consuming and complicated. Both control center and substation encounter the problem of interoperability. The security requirement of power system IT comes with implementation of IT technique in power system. In this section, several standards and guidelines, which are used for considering interoperability and cyber-security problems, are shortly described.

\subsection{Common Information Model}

Common Information Model (CIM) is defined as an abstract model that represents possible objects in an electric utility enterprise typically involved in power system market and operation [34]. IEC 61970 (part 3xx) and IEC 61968 (part 11-13) are the standards, commonly referred as CIM provide a vender-neutral way to represent power system resources as object classes and attributes along with their relationship. CIM facilitates the integration of EMS applications developed by different vendors with proprietary data formats and information exchange between control centers [34]. Specifically, Unified Modeling Language (UML) class diagrams are adopted as a method of visually representing object hierarchies [36]. The eXtensible Markup Language (XML) combined with Resource Description Framework (RDF) provides a file format capable of storing the extended data. Other than inter-operability, CIM also considers system performance. The concept of CIM profile is brought up by CIMug to limit the size of the transferred CIM/XML/RDF payloads [35].

\subsection{Substation Automation Standard}

In order to improve interoperability at substation level, IEC61850 is written. It provides flexible and specific way of data structure building and modeling for the substation devices [37-42]. Vendors need to follow naming rules and conventions while, the standard also allows flexibility of prefix is open to vendor. In order to avoid misunderstood by other vendor, substation description language (SCL) is used to exchange configuration information [43]. Several ways of data exchange for substation communication are described such as Generic Object Oriented Substation Events (GOOSE), Manufacturing Message Specification (MMS), and Sampled Value (SV). Implementation of these types of message also needs to follow the standard way which is defined by IEC61850 [44-46]. Requirement of communication for different applications is also stated in the standard [47].

\subsection{Power System Synchrophasors Standard}

IEEE1344 is the standard for synchrophasors for power system which gives the configuration parameters for PMU and phasor data format and synchronization requirements [48]. C37.118 provides method of quantifying the measurement, quality test specification, accuracy of measurements, and real-time communication protocol [49]. Other relevant standards are referred as well.

Since PMU measurement are inessentially part of measurements collected at the interface to power system, IEC61850 also provide a relevant part 90-5 which is focus on PMU data structure modeling. Data objects, data attributes are mapped into IEC61850 which allow IEC61850 supported PMU can interoperate with other IEC61850 supported devices.

\subsection{Cyber-Security Guides for Power Grid}

As long as there is IT system involved in system operation and control, cyber-security becomes a prioritized concern. The blackout of $14^{\text {th }} 2003$ in U.S. was due to a series of power equipment fault and communications delays of alert responses in control systems [50]. IT infrastructure failure may not only due to deliberate attacks, but also involved with inadvertent mishandling of events, and poor system design. [51] proposes a tool to assess vulnerabilities from cyberattack of SCADA system. [52] proposes a framework of data privacy and data security. [53] focuses on cyber-security 
specifically for wide-area monitoring, protection, and control (WAMPAC) system by identifying possible vulnerabilities. [50] provides guidelines for smart grid cyber security and tool for researching, designing, implementing, and evaluation of cyber security.

\section{FUTURE SYSTEM REQUIREMENTS DISCUSSION}

Security, performance, interoperability, and other non-functional aspect are in the scope of power system requirements in this paper.

\subsection{Security, Performance and Interoperability}

As discussed previously, applications in the power system have different requirements of security, performance and interoperability depending on purposes, relevant extent to other applications, and infrastructure. As in other industries, cost is always the constraint.

Performance of response time in power system applications includes reaction time and process time. As part of performance of power system application, the delay tolerance of applications is another issue to be put emphasis on.

In the legacy SCADA system, data acquisition is polling based communication role. Control center requests data from each RTU, this process is generally referred as poling. RTU receives requests for data reading and responds corresponding data. SCADA system in general has data rate about one sample per two or three seconds [22]. Therefore, the scanning time of whole system needs several seconds to minutes depending on the scales of the grids. Thus, the real-time data acquisition performed by conventional SCADA is far from sufficient to capture power system dynamics.

Substation applications for protection purposes have more stringent requirements comparing to their counterparts at the control centers. Different from copper wired communication, periodical data packets are mainly used in digital communication. Data rate affects the resolution of measurement from receiver point of view. Recent Merging Unit (MU) can support data report rate to 4000 samples per second. PMUs and PDCs can provide even higher data resolution or accuracy to applications. Depends on capability of PMU, the data resolution can be given from tens to ten-kilo samples per second level. PMUs send processed data to application whose report rate is around $50-80$ reports per second.

Data report rate affects application responding to the possible events. Protection applications have highest requirement of data report rate since their responding time should be short after events as much as possible. Increasing data report rate for system control and analysis applications, such as PSS, AGC, state estimation, and etc, can improve control performance [59]. On the other hand, it is not necessary for all applications to have high data report rate which put a higher bandwidth requirement for the communication network. For example, display of overview system status for operator normally does not need to refresh more frequently than 10 seconds [22]. To the normal load management, it is based on bidding period of electricity market which could be hourly, 30 minutes, or even 5 minutes. It is also not necessary for these applications to have high data report rate since communication network efficiency should be considered.

Communication requirements, such as delay, data loss, and etc, are another major concern in the modern power system. Quality of Service (QoS) should be considered in the design stage of the system. Here two main parts of QoS, performance and cyber security are discussed. Cyber security can ensure the safety of data transfer from publishers to subscribers. According to security section partition, communication in power system can be divided into two types mainly. One is local area network (LAN) communication such as internal substation communication or control center local communications. The other shares network resources with wide area network (WAN). For example, PMU need to share the communication infrastructure with other internet user. In first case, cyber security is focus on network reliability, and security function of interface between LAN and WAN. In second case, reliability, cyber-attack and countermeasure, vulnerability should be considered. Latency requirements are given in common point of view. [54] presents the latency requirements based on communication range and type of applications as shown in the table 1.

Table 1: QoS requirement of Applications

\begin{tabular}{|l|l|l|}
\hline $\begin{array}{l}\text { Application } \\
\text { Type }\end{array}$ & $\begin{array}{l}\text { Communication } \\
\text { Range }\end{array}$ & $\begin{array}{l}\text { Maximum } \\
\text { Latency }\end{array}$ \\
\hline \multirow{2}{*}{ Fast-speed } & Intra-substation & $4 \mathrm{~ms}$ \\
\cline { 2 - 3 } & Extra-substation & $8-12 \mathrm{~ms}$ \\
\hline \multirow{2}{*}{ Medium-speed } & Intra-substation & $16 \mathrm{~ms}$ \\
\cline { 2 - 3 } & Extra-substation & $1 \mathrm{~s}$ \\
\hline \multirow{2}{*}{ Low-speed } & Intra-substation & $1-10 \mathrm{~s}$ \\
\cline { 2 - 3 } & Extra-substation & $1-10 \mathrm{~s}$ \\
\hline
\end{tabular}

In table 1, latency means the latency should be better than listed value. The number in range means depends on applications. Intra-substation means data publishers and subscribers are both located in same substation. Otherwise, the applications fall into the category of extrasubstation. The latency requirements for PMU based application is no more than 20-30ms.

For interoperability designer should considers the current system while keeps future expansion in mind. Control center applications are possible to share data with substation applications. Recently, control center level information exchange normally uses CIM standards which are stated in section 4.1. 
Substation level applications use IEC61850 and phasor data applications use C37.118. Actually, these application, no matter belong to which level, is actually sharing the same data sources. Two possible way to solve data sharing problem, one is developing new standards covers whole power system which is obviously impractical. The other is harmonization of the relevant standard clusters. However, latter one has strength of future integration with new devices and new standards.

\subsection{Other non-functional aspects}

Except requirement of security, performance, and interoperability, there are some other nonfunctional aspects such as consistent data across applications and flexibility for future expansion.

In modern power system, control and operation applications might use data source from devices from different vendors with proprietary data formats. A Service Oriented Architecture (SOA) is proposed to improve data consistency which is verified by two use cases, which are presented by [55]. Flexibility for future expansion and modification should be considered as well. Legacy systems are integrated with new devices, new protocols, and new applications to fulfill the new requirement of the system. Flexibility can increase the compatibility of system with new software and hardware and reduce the costs for system expansion

These aforementioned factors could be contradictory meaning enforcing one aspect could degrade the other. A method is presented to model and evaluate the non-functional aspects of integrated protection and control system [15].

\section{FRAMEWORK}

Proposed framework is shown in figure 4. Left part of the figure gives the data flow from transducer at bottom to applications at top. PMU and MU share data source of transducers for different purposes. MU sends sampling data stream to IED via substation process bus. PMU sends phasor data to PDC or direct to super PDC [58]. Data from IED can be achieved by SCADA system directly or via RTU. RTU as substation communication device supports several standards which are used for information exchange between SCADA system and substation. In order to obtain data from IED directly, harmonization of communication standards between control center and substation is needed. PDC, PMU, IED, and RTU are able to use WAN to transport data to control center. Control center application can access data from RTU, IED by SCADA and phasor data from super PDC, which concentrates phasor data from PDC or PMU.

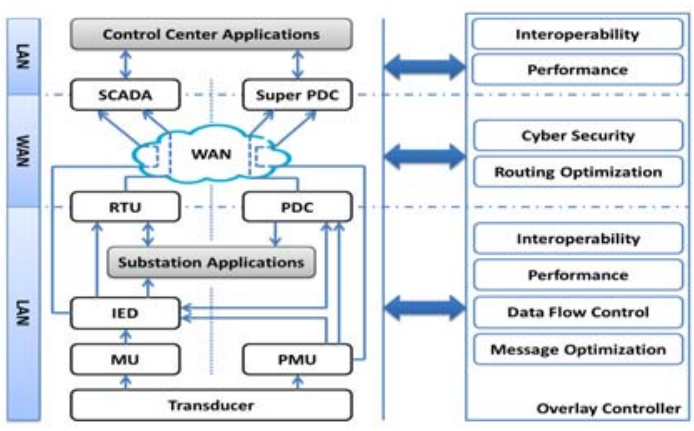

Fig. 4 : Framework Overview

This figure mainly described the vertical communication. Another dimension of communication, horizontal communication between substations is also in the scope of this framework. In the right part of this figure highlights the critical concerns for the data communication. At top part, interoperability and performance need to be considered. CIM model is used for information exchange between control centers. Performance of application in control center layer include requirement of data source, data report rate, latency, and response time. In the middle, data flow goes through wide area network, in this part overlay controller focuses on security of data flow and interface between LAN and WAN. Data flow between substations, control center and substations are included in this layer. In order to control the latency of data flow, routing optimization is mainly applied for data flow control by overlay controller. In bottom layer, data exchange internal substation is considered. Interoperability of different devices i.e., IEDs, RTUs, PMUs, MUs, PDCs, different standards (i.e. IEEE1344, IEC61850, IEC60870 [56]) are in the scope. Substation level applications have requirement of data source, data report rate, data resolution, latency, and responding. Overlay controller handle all these requirements and provide proper data to corresponding applications by message flow control and message design optimization.

\section{CONCLUSIONS}

This paper summarizes the critical concerns for SCADA system which is considered as a legacy comparing to the visioned synchronized phasor based wide-area monitoring and control systems. Moreover, relevant standards that may provide solutions are described. Finally, the system and application requirements are discussed. The framework is proposed to solve the problem of integrating legacy system with phasor data for power system operation and control.

\section{FUTURE WORKS}


According to the framework described above, future work is divided into small but detail directions. Firstly, IT requirement of power system application will be studied. Recent researches of applications are based on ideal data acquisition situation. In reality, latency and data loss is unavoidable during data transmission in wide area network. Impact of latency and data loss will affect the control quality of the project functionality. These requirements will be studied by using test bed combined with communication network simulator and power system simulator. After requirement survey of applications, overlay network management system will be implemented to improving communication network performance for power system applications. Co-simulation between communication simulator (or emulator) and power system simulator will be another interest topic.

\section{REFERENCES}

[1] Dy-Liacco, T.E.; , "Control centers are here to stay," Computer Applications in Power, IEEE , vol.15, no.4, pp.18-23, October 2002

[2] Wu, F.F.; Moslehi, K.; Bose, A.; , "Power System Control Centers: Past, Present, and Future," Proceedings of the IEEE , vol.93, no.11, pp.1890-1908, Nov. 2005

[3] F.F. Wu, Real-time network security monitoring, assessment and optimization, International Journal of Electrical Power \&amp; Energy Systems, Volume 10, Issue 2, April 1988, Pages 83-100

[4] Phadke, A. G.; Thorp, J. S.; Adamiak, M. G.; , "A New Measurement Technique for Tracking Voltage Phasors, Local System Frequency, and Rate of Change of Frequency," Power Engineering Review, IEEE , vol.PER-3, no.5, pp.23, May 1983 [5] Bose, A.; , "Smart Transmission Grid Applications and Their Supporting Infrastructure," Smart Grid, IEEE Transactions on , vol.1, no.1, pp.11-19, June 2010

[6] Kun Zhu; Chenine, M.; Nordstrom, L.; , "ICT Architecture Impact on Wide Area Monitoring and Control Systems' Reliability," Power Delivery, IEEE Transactions on , vol.26, no.4, pp.2801-2808, Oct. 2011

[7] Benigni, A.; Junqi Liu; Ponci, F.; Monti, A.; Pisano, G.; Sulis, S.; , "Decoupling Power System State Estimation by Means of Stochastic Collocation," Instrumentation and Measurement, IEEE Transactions on , vol.60, no.5, pp.16231632, May 2011

[8] Falcao, D.M.; Wu, F.F.; Murphy, L.; , "Parallel and distributed state estimation," Power Systems, IEEE Transactions on , vol.10, no.2, pp.724-730, May 1995

[9] Chaudhuri, N.R.; Domahidi, A.; Majumder, R.; Chaudhuri, B.; Korba, P.; Ray, S.; Uhlen, K.; , "Wide-area power oscillation damping control in nordic equivalent system," Generation, Transmission \& Distribution, IET , vol.4, no.10, pp.1139-1150, October 2010

[10] IEC, Communication Networks and Systems in substations - Part 1: Introduction and overview, IEC Std. 61850-1, 2003.

[11] Phadke, A.G.; Pickett, B.; Adamiak, M.; Begovic, M.; Benmouyal, G.; Burnett, R.O., Jr.; Cease, T.W.; Goossens, J.; Hansen, D.J.; Kezunovic, M.; Mankoff, L.L.; McLaren, P.G.; Michel, G.; Murphy, R.J.; Nordstrom, J.; Sachdev, M.S.; Smith, H.S.; Thorp, J.S.; Trotignon, M.; Wang, T.C.; Xavier, M.A.; "Synchronized sampling and phasor measurements for relaying and control," Power Delivery, IEEE Transactions on , vol.9, no.1, pp.442-452, Jan 1994

[12] Terzija, V.; Valverde, G.; Deyu Cai; Regulski, P.; Madani, V.; Fitch, J.; Skok, S.; Begovic, M.M.; Phadke, A.; , "WideArea Monitoring, Protection, and Control of Future Electric Power Networks," Proceedings of the IEEE , vol.99, no.1, pp.80-93, Jan. 2011
[13] Honeth, N.; Wu Yiming; Etherden, N.; Nordstrom, L.; , "Application of the IEC 61850-7-420 data model on a Hybrid Renewable Energy System," PowerTech, 2011 IEEE Trondheim , vol., no., pp.1-6, 19-23 June 2011

[14] Meliopoulos, A.P.S.; Cokkinides, G.J.; Galvan, F.; Fardanesh, B.; , "Distributed State Estimator Advances and Demonstration," Hawaii International Conference on System Sciences, Proceedings of the 41st Annual , vol., no., pp.163, 710 Jan. 2008

[15] Nordström, L.; Johnson, P.;, "Modelling and Evaluation Non-functional Aspects of Integrated Protection and Control Systems,"System Operation \& Control Preferential Subject, CIGRÉ,pp.1-3,2008

[16] Zima, M.; Larsson, M.; Korba, P.; Rehtanz, C.; Andersson, G.; , "Design Aspects for Wide-Area Monitoring and Control Systems," Proceedings of the IEEE , vol.93, no.5, pp.980-996, May 2005

[17] Farhangi, H.; , "The path of the smart grid," Power and Energy Magazine, IEEE , vol.8, no.1, pp.18-28, JanuaryFebruary 2010

[18] Massoud Amin, S.; Wollenberg, B.F.; , "Toward a smart grid: power delivery for the 21st century," Power and Energy Magazine, IEEE , vol.3, no.5, pp. 34- 41, Sept.-Oct. 2005

[19] Dong Wei; Yan Lu; Jafari, M.; Skare, P.M.; Rohde, K.; , "Protecting Smart Grid Automation Systems Against Cyberattacks," Smart Grid, IEEE Transactions on , vol.2, no.4, pp.782-795, Dec. 2011

[20] Glover,J.D.; Sarma,M.S.; Overbye,T,J.;,"Power System Analysis and Design”, pp.482-535, ISBN-13:978-0-495-295969, CENGAGE Learning 2008

[21] McDonald,J.D.; "Electric Power Substations Engineering”, pp.3-1 - 3-7, ISBN:978-0-8493-7383-1, CRC Press 2007.

[22] Gaushell, D.J.; Darlington, H.T.; , "Supervisory control and data acquisition," Proceedings of the IEEE , vol.75, no.12, pp. 1645- 1658, Dec. 1987

[23] Eriksson, L.; Saha, M.M.; Rockefeller, G.D.; , "An Accurate Fault Locator With Compensation For Apparent Reactance In The Fault Resistance Resulting From Remore-End Infeed," Power Apparatus and Systems, IEEE Transactions on , vol.PAS-104, no.2, pp.423-436, Feb. 1985

[24] John,D.M.; "Electric Power Substations Engineering", ISBN:978-0-8493-7383-1. CRC Press, 2007

[25] Saha,M.M.; Izykowski,J.; Rosolowski,E.; "Fault Location on Power Networks", ISBN:978-1-84882-885-8. Springer, Oct 2009

[26] Martin, K.; Carroll, J.; , "Phasing in the Technology," Power and Energy Magazine, IEEE , vol.6, no.5, pp.24-33, September-October 2008

[27] Zhu,K.; Ahmad,T. A.; Nordström, L.; ”To Concentrate or not to Concentrate: Performance Analysis of ICT system with Data Concentrations for Wide-area Monitoring and Control System”, Power Engineering Society General Meeting, 2007. IEEE , vol., no., 2012

[28] Chenine, M.; Vanfretti, L.; Bengtsson, S.; Nordstroum, L.; , "Implementation of an experimental wide-area monitoring platform for development of synchronized phasor measurement applications," Power and Energy Society General Meeting, 2011 IEEE , vol., no., pp.1-8, 24-29 July 2011

[29] Yingchen Zhang; Markham, P.; Tao Xia; Lang Chen; Yanzhu Ye; Zhongyu Wu; Zhiyong Yuan; Lei Wang; Bank, J.; Burgett, J.; Conners, R.W.; Yilu Liu; , "Wide-Area Frequency Monitoring Network (FNET) Architecture and Applications," Smart Grid, IEEE Transactions on , vol.1, no.2, pp.159-167, Sept. 2010

[30] De La Ree, J.; Centeno, V.; Thorp, J.S.; Phadke, A.G.; "Synchronized Phasor Measurement Applications in Power Systems," Smart Grid, IEEE Transactions on , vol.1, no.1, pp.20-27, June 2010

[31] Phadke, A.G.; Thorp, J.S.; , "Communication needs for Wide Area Measurement applications," Critical Infrastructure (CRIS), 2010 5th International Conference on , vol., no., pp.1-7, 20-22 Sept. 2010

[32] Yang Zhang; Bose, A.; , "Design of Wide-Area Damping Controllers for Interarea Oscillations," Power Systems, IEEE Transactions on , vol.23, no.3, pp.1136-1143, Aug. 2008 
[33] Adamiak, M.G.; Apostolov, A.P.; Begovic, M.M.; Henville, C.F.; Martin, K.E.; Michel, G.L.; Phadke, A.G.; Thorp, J.S.; , "Wide Area Protection-Technology and Infrastructures," Power Delivery, IEEE Transactions on , vol.21, no.2, pp. 601- 609, April 2006

[34] IEC 61970-301 Common Information Model Base, third edition, revision 018

[35] IEC 61970-452 CIM Transmission Network Model Exchange Profiles Draft, revision 6.07

[36] McMorran, A.W.; "An Introduction to IEC 61970-301 61968-11: The Common Information Model," University of Strathclyde, 2007

[37] IEC, Communication Networks and Systems in Substations - Part 7-1: Basic Communication Structure for Substation and Feeder Equipment-Principles and models, IEC Std. 61850-7-1, 2003.

[38] IEC, Communication Networks and Systems in Substations - Part 7-2: Basic Communication Structure for Substation and Feeder Equipment-Abstract Communication Service Interface (ACSI), IEC Std. 61850-7-2, 2003.

[39] IEC, Communication Networks and Systems in Substations - Part 7-3: Basic Communication Structure for Substation and Feeder Equipment-Common Data Classes, IEC Std. 61850-7-3, 2003.

[40] IEC, Communication Networks and Systems in Substations - Part 7-4: Basic Communication Structure for Substation and Feeder Equipment-Compatible Logical Node Classes and Data Classes, IEC Std. 61850-7-4, 2003

[41] IEC, Communication Networks and Systems for Power Utility Automation - Part 7-410: Hydroelectric Power Plants Communication for Monitoring and Control, IEC Std. 61850-7410, 2006.

[42] IEC, Communication Networks and Systems for Power Utility Automation - Part 7-420: Basic Communication Structure - Distributed Energy Resources Logical Nodes, IEC Std. 61850-7-420, 2009.

[43] IEC, Communication Networks and Systems in Substations - Part 6: Configuration Description Language for Communication in Electrical Substations Related to IEDs, IEC Std. 61850-6, 2004.

[44] IEC, Communication Networks and Systems in Substations - Part 8-1: Specific Communication Service Mapping (SCSM)Mapping to MMS(ISO9506-1 and ISO9506-2) and to ISO/IEC8802-3, IEC Std. 61850-8-1, 2004.

[45] IEC, Communication Networks and Systems in Substations - Part 9-1: Specific Communication Service Mapping (SCSM)Sampled Values over Serial Unidirectional Multidrop Point to Point Link, IEC Std. 61850-9-1, 2003.

[46] IEC, Communication Networks and Systems in Substations - Part 9-1: Specific Communication Service Mapping (SCSM)Sampled values over ISO/IEC8802-3, IEC Std. 61850-9-1, 2003.

[47] IEC, Communication Networks and Systems in Substations - Part 5: Communication Requirements for Functions and Device Models, IEC Std. 61850-5, 2003.

[48] "IEEE Standard for Synchrophasers for Power Systems," IEEE Std 1344-1995(R2001), vol., no., pp.i, 1995

[49] "IEEE Standard for Synchrophasor Data Transfer for Power Systems," IEEE Std C37.118.2-2011 (Revision of IEEE Std C37.118-2005) , vol., no., pp.1-53, Dec. 282011

[50] NIST, "Introduction to NISTIR 7628 Guidelines for Smart Grid Cyber Security”, The Smart Grid Interoperability Panel, Cyber Security Working Group, September 2010, http://csrc.nist.gov/publications/nistir/ir7628/introduction-tonistir-7628.pdf

[51] INL, "Common Cyber Security Vulnerabilities Observed in Control System Assessments by the INL NSTB Program", Technical Report, Idaho National Laboratory, Nov. 2008

[52] EU DG Energy, Taskforce Smartgrids, Expert Froup 2, Regulatory Recommendations for Data Safety, Data Handling and Data Protection. June 2010, http://ec.europa.eu/energy/gas_electricity/smartgrids/doc/expert group2.pdf

[53] The Advanced Security Acceleration Project for the Smart Grid (ASAP-SG), "Security Profile for Wide-Area Monitoring,
Protection, and Control”, UCA International User Group, The UCAIug SG Security Working Group, May 2011

[54] David, E. Bakken; Carl, H. Hauser; Harald Gjermundrød; Anjan Bose;, "Towards More Flexible and Robust Data Delivery for Monitoring and Control of the Electric Power Grid,” Technical Report EECS-GS-009, School of Electrical Engineering and Computer Science, Washington State University, May 2007 available on: http://gridstat.net/trac/wiki/publications\#

[55] Svensson, E.; Vetter, C.; Werner, T.; "Data consistency in a heterogeneous IT landscape: a service oriented architecture approach," Enterprise Distributed Object Computing Conference, 2004. EDOC 2004. Proceedings. Eighth IEEE International , vol., no., pp. 3- 8, 20-24 Sept. 2004

[56] Martin, K.E.; , "Synchrophasor Standards Development IEEE C37.118 \& IEC 61850," System Sciences (HICSS), 2011 44th Hawaii International Conference on , vol., no., pp.1-8, 4-7 Jan. 2011

[57] Nuqui, R.F.; Phadke, A.G.; , "Hybrid Linear State Estimation Utilizing Synchronized Phasor Measurements," Power Tech, 2007 IEEE Lausanne , vol., no., pp.1665-1669, 1-5 July 2007

[58] K. Zhu, A.T. Al-Hammouri, L. Nordström,; "Examination of data delay and packet loss for Wide-Area Monitoring and Control Systems," In 2nd ENERGYCON Conference \& Exhibition, 2012 - ICT for Energy, Sep, 2012.

[59] Y. Chompoobutrgool, L. Vanfretti, M. Ghandhari.; "Survey on Power System Stabilizers Control and their Prospective Applications for Power System Damping using SynchrophasorBased Wide-Area Systems,” John Wiley \& Sons; European transactions on electrical power. 2011; 21(8):2098-2111. 